\title{
Lymphocytic Infundibuloneurohypophysitis: Long- Term Follow-Up of a Case Cured with Glucocorticoid
}

\author{
Hidefumi Inaba Satoru Suzuki Satoshi Shigematsu Masahiro Takei Takahide Miyamoto \\ Teiji Takeda Keishi Yamauchi Kiyoshi Hashizume \\ Department of Aging Medicine and Geriatrics, Shinshu University School of Medicine, Matsumoto, Japan
}

\section{Key Words}

Lymphocytic infundibuloneurohypophysitis • Pituitary gland $\cdot$ Steroid therapy $\cdot$ Diabetes insipidus

\begin{abstract}
Objective: To report a case of infundibuloneurohypophysitis treated with steroid. Clinical Presentation: A 65-year-old woman who was well until 4 weeks before admission and was not taking any medication presented with acute development of polydipsia and polyuria. Urinary volume was increased to $4,500 \mathrm{ml} /$ day. She showed elevated serum osmolality and low urine osmolality, together with shortage of antidiuretic hormone. Magnetic resonance imaging (MRI) of the pituitary revealed marked nodular thickening of the neurohypophysis. Endocrinologically, anterior pituitary function appeared normal. Based on these examinations, she was diagnosed as having central diabetes insipidus due to lymphocytic infundibuloneurohypophysitis. Intervention: Prednisolone (1 mg/kg/day, p.o.) and D-deaminovasopressin ( $5 \mu \mathrm{g} /$ day, intranasal) were commenced. Ten days after the administration of the agents, MRI showed a dramatic improvement in the thickening of the neurohypophysis. Ten weeks later, abnormalities found in earlier MRI had disappeared. The drugs were withdrawn gradually, and diabetes insipidus ceased 25 weeks later. Recurrence was not seen in the subsequent MRI, and the function of the posterior pituitary gland was completely normalized even 7 years after discontinuation of treatments. Conclusion: This case shows that noninvasive diagnosis and appropriate steroid administration can effectively cure lymphocytic infundibuloneurohypophysitis; it is recommended with long-term follow-up.
\end{abstract}

Copyright $\odot 2009$ S. Karger AG, Basel

\section{KARGER}

Fax +4161306 1234

E-Mail karger@karger.ch

www.karger.com
(C) 2009 S. Karger AG, Basel

$1011-7571 / 10 / 0191-0079 \$ 26.00 / 0$

Accessible online at:

www.karger.com/mpp

\section{Introduction}

Lymphocytic infundibuloneurohypophysitis (LINH) is an inflammatory state in the posterior pituitary lobe that manifests itself in diabetes insipidus and often develops crucial panhypopituitarism [1-5]. Diagnosis of LINH is complicated because pituitary biopsy for diagnosis often causes serious complications $[4,5]$. Since autoimmunity is thought to be the underlying cause, steroid therapy is recommended for LINH $[6,7]$. Nevertheless, complete recovery of posterior pituitary function is hardly obtained, and long-term information is seldom available [4, 5]. To elucidate these issues, we report a case of LINH appropriately treated with steroid in the long-term followup with useful markers.

\section{Case Report}

A 65-year-old woman suffering from an acute development of polyuria and polydipsia was admitted to our hospital in 2002. Urine volume was $4,500 \mathrm{ml} /$ day. Four weeks before admission, she was well and not taking any medication. She was $150 \mathrm{~cm}$ in height and $50.2 \mathrm{~kg}$ in weight. She had lost $2 \mathrm{~kg}$ during the last month. Blood pressure was $126 / 80 \mathrm{~mm} \mathrm{Hg}$. Body temperature was $36.4^{\circ} \mathrm{C}$. Heart and chest sounds were normal.

She showed elevated serum osmolality of $305 \mathrm{mosm} / \mathrm{kg} \mathrm{H} \mathrm{H}_{2} \mathrm{O}$ and low urine osmolality of $101 \mathrm{mosm} / \mathrm{kg} \mathrm{H}_{2} \mathrm{O}$. Serum sodium level was $150 \mathrm{mmol} / \mathrm{l}$. Plasma antidiuretic hormone concentration was subnormal: $0.45 \mathrm{pg} / \mathrm{ml}$ (normal range 0.3-4.2). All anterior pituitary hormones were within normal limits, except for high serum prolactin (PRL) concentration, $37.3 \mathrm{ng} / \mathrm{ml}$ (normal range 515). Both antipituitary cell antibodies and antipituitary cell surface antibodies in serum were negative. Antinuclear antibody was negative. Diabetes mellitus was ruled out because of normal fast- 
Fig. 1. a Unenhanced sagittal $T_{1}$-weighted image revealed thickening of the stalk and enlargement of the neurohypophysis. Hyperintense signal of the posterior lobe had disappeared. b Sagittal $\mathrm{T}_{1}$-weighted gadolinium-enhanced image demonstrated that both stalk and pituitary gland were enhanced homogeneously after a drip of Gd-DTPA.
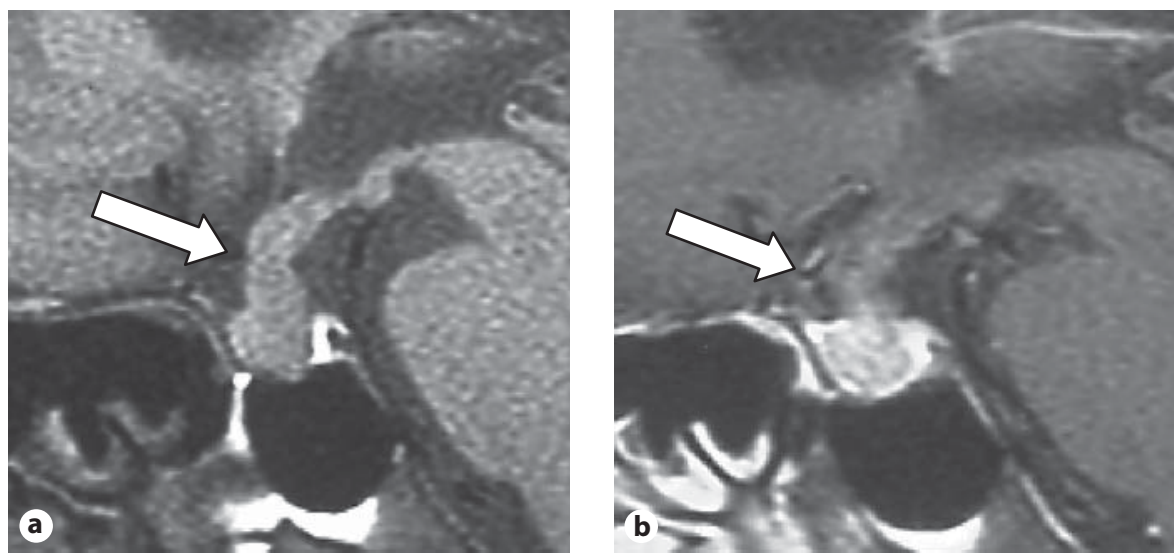

Fig. 2. Clinical course of LINH. Treatment with DDAVP (5 $\mu \mathrm{g} /$ day) and PSL ( $1 \mathrm{mg} /$ $\mathrm{kg})$.

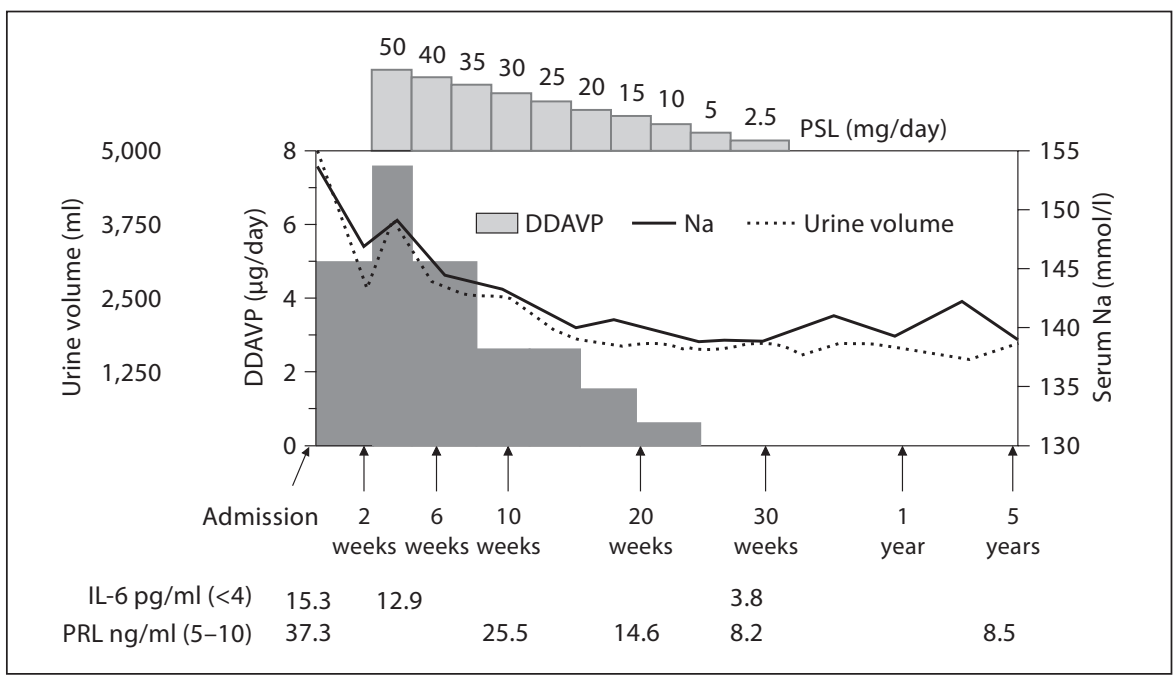

Fig. 3. a MRI 10 days after PSL treatment showed reappearance of the $\mathrm{T}_{1}$-weighted hyperintense signal in the posterior lobe. b MRI 10 weeks after PSL treatment. The thickening of the hypophyseal stalk and the swelling of the pituitary gland had remarkably improved.
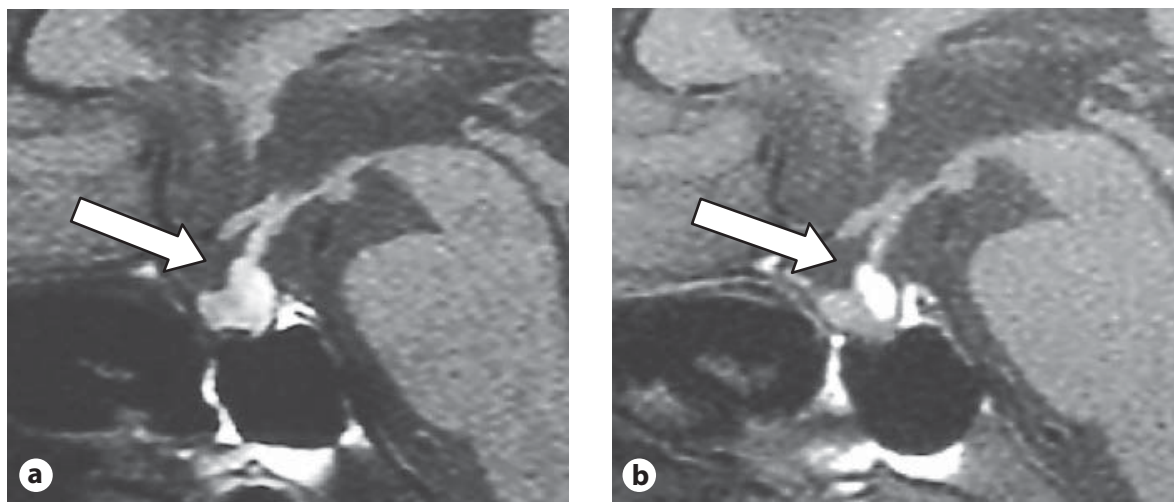

ing plasma blood glucose and glycosylated hemoglobin levels. Complete blood count was normal. C-reactive protein and erythrocyte sedimentation rate were also normal. Plasma concentration of interleukin-6 (IL-6) was elevated to $15.3 \mathrm{pg} / \mathrm{ml}$ (normal <4). Tumor markers examined were negative. HIV test was negative. Tuberculin test was normal. Plasma angiotensin-converting enzyme determined by RIA was normal. Thyroid function was normal, and antithyroid antibodies were negative. Adrenal function was normal. In pituitary provocation tests $(\mathrm{LHRH}, \mathrm{CRH}, \mathrm{TRH}$, and GRH tests), the response of GH to GRH showed a normal but delayed peak value, suggesting mild hypophyseal impairment. Cerebrospinal fluid (CSF) did not show aberration in cytology. There were no abnormal findings in electrocardiogram, chest X-ray, abdominal CT, and gastrointestinal tract endoscopy.

Magnetic resonance imaging (MRI) of the pituitary gland revealed a marked nodular thickening of the neurohypophysis, with 
swelling of the hypophyseal stalk and the infundibulum (fig. 1a). They were enhanced homogeneously after injection of Gd-DTPA (fig. 1b). A normal hyperintense signal in the neurohypophysis was absent in $\mathrm{T}_{1}$-weighted images. Numerous diseases, including tumoral diseases, infectious diseases, and diabetes insipidus were ruled out by clinical state, MR images, and CSF results without abnormal cells. Langerhans cell histiocytosis and other granulomatous diseases such as sarcoidosis and Wegener's granulomatosis were less likely. Based on the clinical manifestation, findings of pituitary MRI and endocrinological and CSF examinations, the patient was diagnosed as having central diabetes insipidus possibly due to LINH $[4,5,8,9]$.

Treatment with prednisolone (PSL, $1 \mathrm{mg} / \mathrm{kg} /$ day, p.o.) and nasal drip of D-deaminovasopressin (DDAVP, $5 \mu \mathrm{g} /$ day) were started together (fig. 2). Serum and urine osmolality were normalized with DDAVP. The amount of PSL was gradually decreased every 2 weeks (approximately 10\% reduction of previous dosage). DDAVP was unnecessary 25 weeks after initial treatment; however, PSL was continued 7 weeks thereafter, following our protocol. Plasma concentration of IL-6 decreased to $12.9 \mathrm{pg} / \mathrm{ml} 10$ days after the PSL treatment. At 10 weeks, PRL had decreased to 25.5 $\mathrm{ng} / \mathrm{ml}$ (fig. 2). At 30 weeks, both PRL and IL-6 concentration were normalized to 8.2 and $3.8 \mathrm{pg} / \mathrm{ml}$, respectively. Even 7 years after cessation of steroid, recurrence has not been observed in MRI examinations, and whole pituitary function is preserved.

Examination with an MRI 10 days after the beginning of PSL administration showed a dramatic improvement of the infundibular and pituitary thickening with a reappearance of the $\mathrm{T}_{1^{-}}$weighted hyperintense signal in the neurohypophysis (fig. 3a). Ten weeks later, the previously abnormal findings in the MRI had completely disappeared (fig. 3b).

\section{Discussion}

As demonstrated, steroid therapy was effective in our case in the long-term follow-up. It is very rare to obtain improvement not only in MRI but also in posterior pitu- itary function $[4,5]$. Normalization of PRL level was also obtained by PSL therapy, indicating that improvement of pituitary function was completed by PSL therapy in our case. IL-6, a cytokine delivered during inflammation [10], also decreased after treatment, suggesting the improvement of inflammation in the pituitary. These data suggest that PSL and IL- 6 are suitable as markers of the disease. Slow withdrawal of PSL 10 weeks after diabetes insipidus had disappeared seemed effective in this case; however, the reason for this is not clear.

There are many cases that require a transsphenoidal approach for diagnosis as reported previously $[2,3]$. Considering that such an approach could have complications such as hypopituitarism, hemorrhage, infection and CSF rhinorrhea, pituitary biopsy is controversial. In our case, anterior pituitary function was almost preserved, and the inflammation was thought to be limited to the posterior pituitary, and the onset was acute. Thus steroid therapy based on noninvasive diagnosis was chosen. Furthermore, the therapy was beneficial to our patient and as such could be of benefit to those patients who may have risks of surgical damage. Hence we recommend that steroid therapy should be started at the initial stage of the disease if the side effects of steroids are not an issue. However, we also recommend meticulous observation for the emergence of lymphoma or other diseases after PSL therapy [11].

\section{Conclusion}

This case shows that noninvasive diagnosis of LINH and appropriate steroid administration are efficacious and are recommended in the long-term follow-up.

\section{References}

$>1$ Amagasa M, Yuda F, Kojima H, Noshita N, Sato S: Natural course of lymphocytic infundibuloneurohypophysitis. Clin Neuropathol 2001;20:229-232.

2 Ouma JR, Farrell VJ: Lymphocytic infundibulo-neurohypophysitis with hypothalamic and optic pathway involvement: report of a case and review of the literature. Surg Neurol 2002;57:49-54.

3 Nishioka H, Ito H, Sano T, Ito Y: Two cases of lymphocytic hypophysitis presenting with diabetes insipidus: a variant of lymphocytic infundibulo-neurohypophysitis. Surg Neurol 1996;46:285-291.

$\checkmark 4$ Caturegli P, Newschaffer C, Olivi A, Pomper MG, Burger PC, Rose NR: Autoimmune hypophysitis. Endocr Rev 2005;26:599-614. $\checkmark 5$ Imura H, Nakao K, Shimatsu A, Ogawa Y, Sando T, Fujisawa I, Yamabe H: Lymphocytic infundibuloneurohypophysitis as a cause of central diabetes insipidus. N Engl J Med 1993;329:683-689.

6 Kristof RA, Van Roost D, Klingmuller D, Springer W, Schramm J: Lymphocytic hypophysitis: non-invasive diagnosis and treatment by high dose methylprednisolone pulse therapy? J Neurol Neurosurg Psychiatry 1999;67:398-402.

7 Jo YS, Lee HJ, Rha SY, Hong WJ, Song CJ, Kim YK, Ro HK: Lymphocytic hypophysitis with diabetes insipidus: improvement by methylprednisolone pulse therapy. Korean J Intern Med 2004;19:189-192.
8 Abe T: Lymphocytic infundibulo-neurohypophysitis and infundibulo-panhypophysitis regarded as lymphocytic hypophysitis variant. Brain Tumor Pathol 2008;25:5966.

$\checkmark 9$ Abe T, Matsumoto K, Sanno N, Osamura Y: Lymphocytic hypophysitis: case report. Neurosurgery 1995;36:1016-1019.

10 Kishimoto T: The biology of interleukin-6. Blood 1989;74:1-10.

11 Aozasa K, Ohsawa M, Yamabe H, Shima N, Kirimoto K, Yamane T, Tsujimoto M, Kobayashi Y, Kurata A, Osada H: Malignant lymphoma of the central nervous system in Japan: histologic and immunohistologic studies. Int J Cancer 1990;45:632-636. 